\title{
IN-PROCESS MEASUREMENT AND NUMERICAL DETERMINATION OF THE TEMPERATURE IN THE CONTACT ZONE DURING SINGLE LIP DEEP HOLE DRILLING
}

\author{
R. Wegert ${ }^{1 *}$, V. Guski ${ }^{2}$, H.-C. Moehring ${ }^{1}$, S. Schmauder ${ }^{2}$ \\ ${ }^{1}$ University of Stuttgart, Institute for Machine Tools (IfW), 70174 Stuttgart, Germany \\ ${ }^{2}$ University of Stuttgart, Institute for Materials Testing, Materials Science and Strength of Materials (IMWF), \\ 70569 Stuttgart, Germany \\ *Corresponding author; e-mail: robert.wegert@ifw.uni-stuttgart.de
}

\begin{abstract}
In this presented work, the main objective is the in-process measurement of the thermal as-is state near the drilling contact zone by means of a sensor-integrated tool for single lip deep hole drilling (SLD). Additionally, the mechanical quantities feed force and drilling torque are evaluated. The process monitoring is essential to optimize the surface quality as well as the subsurface properties such as hardness and residual stresses. These quantities are strongly dependent on the thermo-mechanical asis state in the cutting zone and in the contact zone between the guide pads and the drill hole surface. This contribution gives a project overview including the development of a sensor-integrated single lip deep hole driller for the in-process temperature measurement, the integration of sensor systems in the tool as well as the experimental investigations on the temperature, the feed force and the drilling torque during drilling of a $42 \mathrm{CrMo} 4$ steel. The temperature measurement at eleven positions in the driller head provides data to observe the heat generation, distribution, and flow independently from the workpiece characteristics. However, one of the greatest benefits is the non-destructive fashion of the measurement system with their sensor integrated in the tool and thus the reusability. A simulation method, which uses the experimental results as a reference, is used to predict the thermo-mechanical conditions in the contact zone of the drill head and the workpiece. The results of these thermo-mechanical process simulations and the validation of this applied FE approach using the measured quantities are presented, too. The results of this work are part of an interdisciplinary research project in the framework of the priority program "Surface Conditioning in Machining Processes" (SPP 2086) of the German Research Foundation (DFG).
\end{abstract}

\section{Keywords:}

Single lip deep hole drilling; monitoring; process temperature; in-process measurement; simulation methods

\section{INTRODUCTION}

According to VDI 3208, the SLD method is used for drillings with a diameter $D$ of $0.5 \mathrm{~mm}$ to $80 \mathrm{~mm}$ and a depth I of $3 \mathrm{D}$ to $250 \mathrm{D}$. In individual cases depths up to $900 \mathrm{D}$ can be achieved [Biermann 2018]. Single lip deep hole drilling is performed with single-edged tools whose circumferential radial passive force is supported by guide pads on the wall of the hole. The interaction between tool and workpiece in combination with cutting and forming at the cutting edge and the guide pads allows the production of holes with high surface quality and accuracy, which also possess a subsurface with compressive residual stresses. The cooling lubricant, which is required to remove chips, is fed at comparatively high pressure through the tool to the machining point, where it collects the resulting chips and transports them outwards in a corrugation on the outside of the tool. Drill holes in components under dynamic loads, such as hydraulic components, which are subjected to pressure changes, or components of injection systems, are often machined using the SLD process. With this SLD process the high demands on the surface quality can be achieved. Besides, compressive residual stresses can be introduced in the resulting drill hole wall. Nevertheless, subsequent process steps, e.g. autofrettage for commonrails, are often necessary to improve the subsurface properties of the deep holes. The novelty in this work is the adjustment of these subsurface properties specifically based on measured in-process conditions by a sensorintegrated tool applying a control loop. For this purpose, a sensor-based control system will be developed that can react to individual process conditions, which are recorded by a measurement technology. In this control loop, the controlled variables are represented by individual subsurface properties and the surface quality. The process 
can be controlled by adjusting the cutting parameters and the cooling lubricant conditions. Therefore, the contro deviation need to be determined and the thermomechanical state in-process need to be monitored, respectively. The monitoring of the thermal state was realized with a sensor-integrated tool. The development of the sensory SLD and the first validation experiments are the focus of this paper. Both, tests under dry conditions as well as cutting tests with cooling lubricant were carried out. These experimental data were used to represent heat exchange conditions in the simulation realistically. In addition, the sensor-based tool concept is tested under realistic conditions to identify optimization potential for the next tool generation. Several ways exist to measure the thermal condition near the cutting zone during single-lip deep hole drilling on the workpiece or tool side [Davies 2007]. Within the scope of the priority program "Surface Conditioning in Machining Processes" (SPP 2086), temperature measurements have been already carried out on the workpiece side using a thermography system and thermocouples [Wegert 2020a, b]. Several experimental, empirical, analytical and numerical methods have been developed to determine the temperatures in-process while metal cutting [Bagci 2006]. Studies of in-process temperature monitoring with thermo-couples on the tool side during twist drilling have also been conducted and compared with results from numerical simulations [Lazoglu 2017]. In this paper a SLD process is presented, which is equipped with 11 resistance temperature sensors. These PT100 sensors are inherently simple and highly accurate because of the linear behavior over a wide temperature range [Davies 2007].

\section{SENSOR INTAGRATION IN THE TOOL}

A sensory tool has been developed for monitoring the thermal state close to the cutting zone, which is equipped with 11 PTC temperature sensors. The sensors are combined to PCB modules and placed underneath the cutting insert and under the guide pads in the driller head. The temperature sensors were referenced to the measured room temperature in the initial state in the tool and additionally with the help of a hot-air gun. To limit the deviation the wire resistances were considered in LabVIEW. Here, no significant drift was observed in the reference measurements with a hot-air gun at $100{ }^{\circ} \mathrm{C}$. The sensor positions are shown in Fig. 1 and Fig. 2. The used EB800 single lip deep hole drill, which has a nominal outer diameter of $D=18 \mathrm{~mm}$ was provided by the company Guehring KG. For sensor integration, the drill head was machined at the Institute for Machine Tools (IfW). In addition to the restricted available space in the tool, the wire routing over a length of $644 \mathrm{~mm}$ within the coolant channel and the required insulation against the coolant are further challenges in the preparation of the SLD tool. The sensor modules were embedded in epoxy resin, but the measuring surfaces of the sensors are exposed and in contact with the cutting insert or the guide pads. This approach has the advantage that the standard cutting inserts and guide pads can be used. Thus, they can be easily replaced as soon as they are worn out. To improve the heat transfer, heat conductive paste was applied to the contact surfaces. A multi-sensory temperature measurement method, in the area of the cutting insert in connection with an inverse FE approach, has already been validated in initial dry machining tests for temperature measurement with the sensory tool [Wegert 2020c].

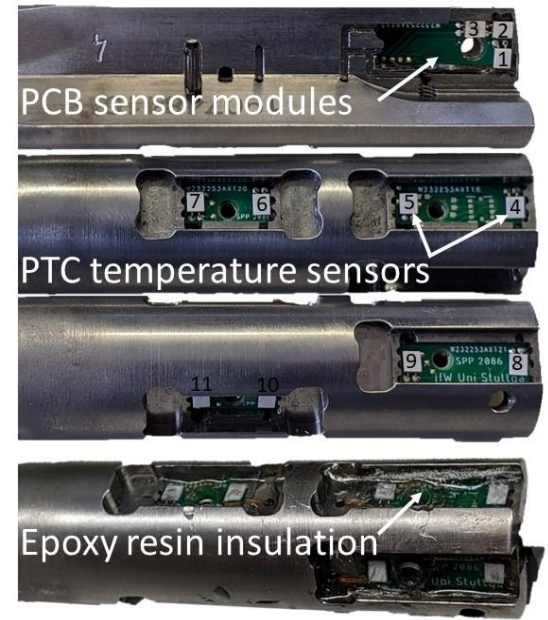

Fig. 1: Sensor-integrated SLD EB800 for temperature measurement.

Since the sensor positions are precisely defined (see Fig. 2), the numerical simulation can be referenced and the heat flow from the heat source into the tool can be investigated.

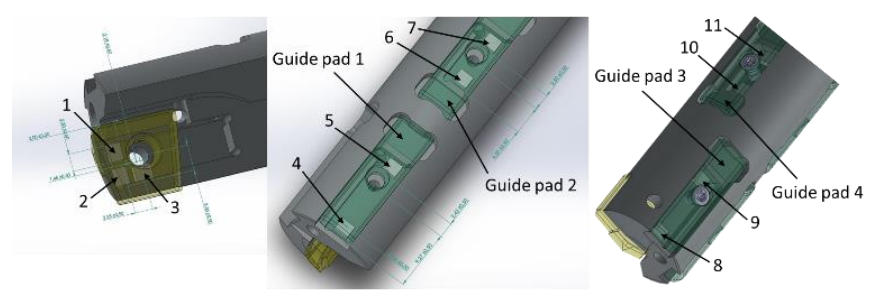

Fig. 2: Temperature sensor positions in the driller head of EB800.

\section{IN PROCESS TEMPERATURE MEASUREMENT IN THE CONTACT ZONE}

The experimental investigations were performed on the deep hole drilling machine Mö-TM-HF-16-2-S from Walter Moeck GmbH.

\subsection{Experimental set up}

As shown in the experimental setup in Fig. 3, the tool was firmly clamped in a vice. The workpiece, on the other hand, was clamped in a KISTLER 9125A rotary dynamometer in the spindle, thus the feed force and the drilling torque were measured on the workpiece side. The cooling lubricant supply of the tool was realized via a specially manufactured adapter. The connection for the volume flow measurement and the pressure measurement were integrated into the adapter. Usually, the cooling lubricant is supplied via the spindle. For the wiring of the 11 PTC sensors PTFE insulated copper wires were used. Connecting the sensors to the measuring card PXle-4357 the wires were led over the cooling channel of the shank. Then the resistancechange was detected, converted into temperatures using the LabVIEW software and evaluated, finally. The specimen is a cylindrical workpiece with an outer diameter of $25 \mathrm{~mm}$ and length of $100 \mathrm{~mm}$ made of $42 \mathrm{CrMo} 4$ tempered and quenched steel. Usually, the samples were prepared with a pilot hole with a depth of $1.5 \mathrm{D}$. 


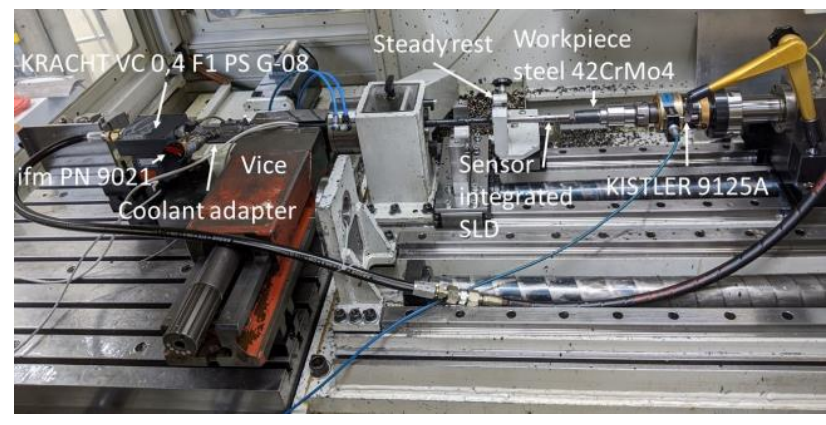

Fig. 3: Experimental set up for in-process temperature measurement while single lip deep hole drilling.

\subsection{Measurements}

First, the drilling test was performed under dry conditions to create a reference for the FE simulations. The cutting speed was $v_{c}=80 \mathrm{~m} / \mathrm{min}$ and the feed rate $f=0.03 \mathrm{~mm} / \mathrm{rev}$. Afterwards, the drilling test was performed under realistic deep drilling conditions with the same cutting parameters but using coolant under a pressure of $p=25$ bar and a flow rate of $\dot{V}=15 \mathrm{~L} / \mathrm{min}$. Each drilling test was repeated three times.

\subsection{Evaluation of the results applying a cooling lubricant}

First, the test results using the cooling lubricant under a pressure of $p=25$ bar are presented. Usually, such a pressure is in the lower range of the applied pressures in SLD drilling processes. In Fig. 4 the temperature measurements under the cutting insert are shown. As mentioned above, a reliable insulation of the sensor system is a challenge, since cooling lubricant acts on the adhesive at a high pressure mixed with chips to be removed. Therefore, different adhesives were evaluated under these rough conditions. The drill rotates in the pilot hole for approx. $38 \mathrm{~s}$, which is reflected in temperature fluctuations in a comparatively low range. After that, the cutting insert starts to engage the solid material. At this moment, when the temperature rises sharply, sensors 1 and 2 fail. Sensor 3 recorded the temperatures during the entire process duration, which is initially sufficient for the calibration of the FE simulation. The displayed temperature curve is the mean value after three passes. The error bars marked in the same color but one step lighter show the $95 \%$ confidence interval. The confidence interval of the mean is the product of the standard error SE and the critical $\mathrm{t}$-value tcrit for $\mathrm{n}-1$ degrees of freedom and a confidence of $95 \%$, where $n$ is the number of measured values. Fig. 4 shows, that the test results are reproducible. In the steadystate the temperature maximum is $55^{\circ} \mathrm{C}$.

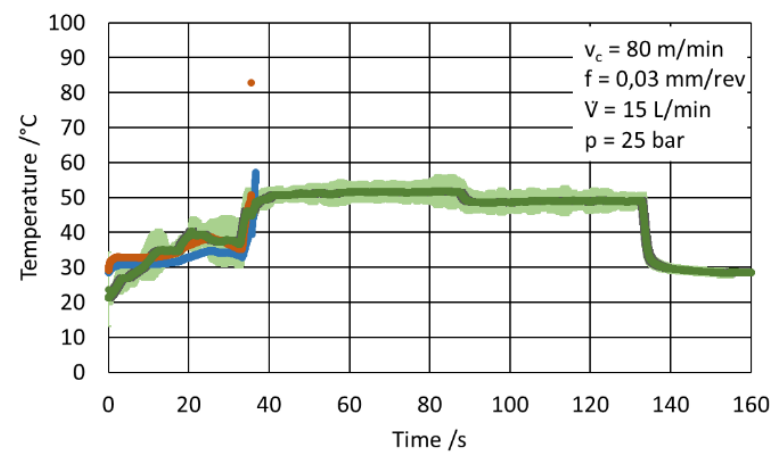

- PTC 1 - PTC 2 - PTC 3 mean

Fig. 4: Temperature curves measured under the cutting insert with use of cooling lubricant.
Fig. 5 shows the temperatures below the front guide pad 1 , which is offset by $87^{\circ}$ to the cutting plate. Sensor 5 failed at the beginning of the drilling process, which is indicated by the extreme temperature gradient after $30 \mathrm{~s}$. With sensor 4 , which is closer to the tool tip, the temperatures were recorded three times. The measured temperatures of approx. $33^{\circ} \mathrm{C}$ are unexpectedly low.

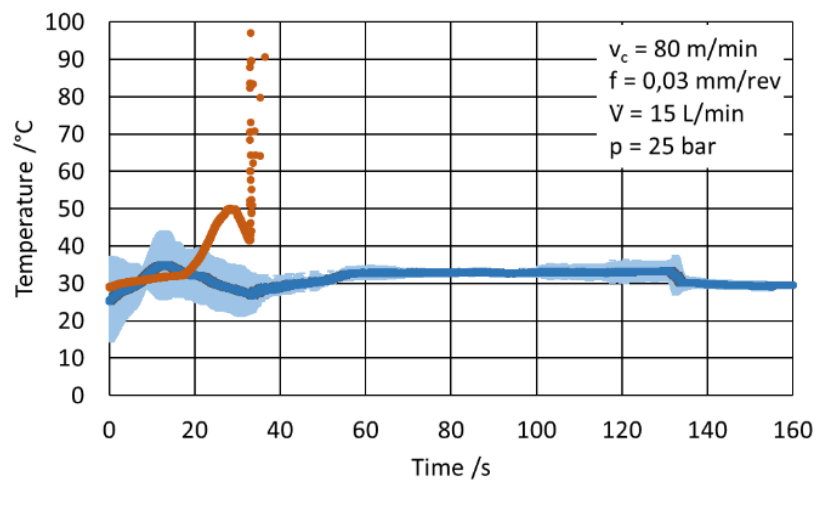

- PTC 4 mean - PTC 5

Fig. 5: Temperature curves measured under the guide pad 1 on the positions 4 and 5 with use of cooling lubricant.

Sensors 6 and 7 are located under the rear guide pad 2, which is also offset by $87^{\circ}$. The temperatures in the steady state reach similar values, see Fig. 6 , compared to the front guide pad 1, although the confidence interval is wider. It can be clearly seen that the temperature at position 6 rushes ahead, since the sensor is closer to the cutting zone at this point.

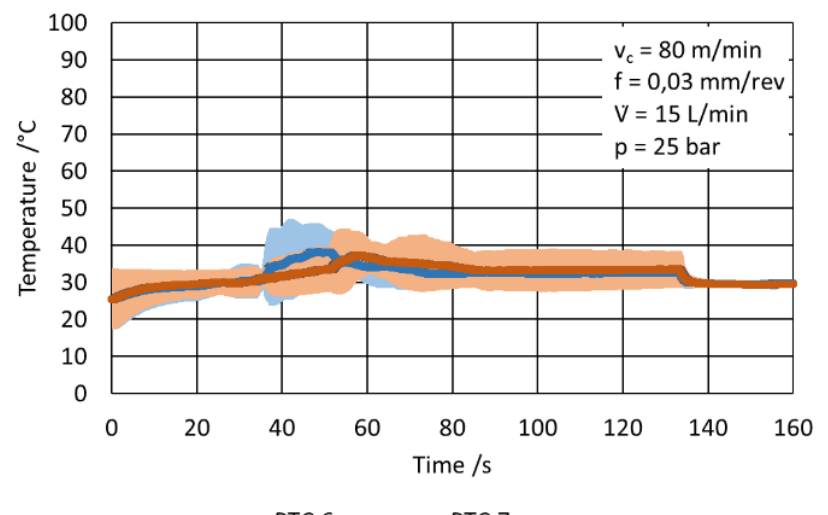

Fig. 6: Temperature curves measured under guide pad 2 on the positions 6 and 7 with use of cooling lubricant.

The sensors 8 and 9 are located underneath the guide pad 3 , which is offset by $163^{\circ}$ to the cutting insert, i.e. almost behind the cutting plate. The average temperatures at the front sensor are around $60{ }^{\circ} \mathrm{C}$ and at the rear sensor around $50{ }^{\circ} \mathrm{C}$, see Fig. 7. This is up to $30^{\circ} \mathrm{C}$ higher than the temperature at the other front guide pad 1 . The magnitude of the values measured at this position is close to the values measured directly under the cutting insert. 


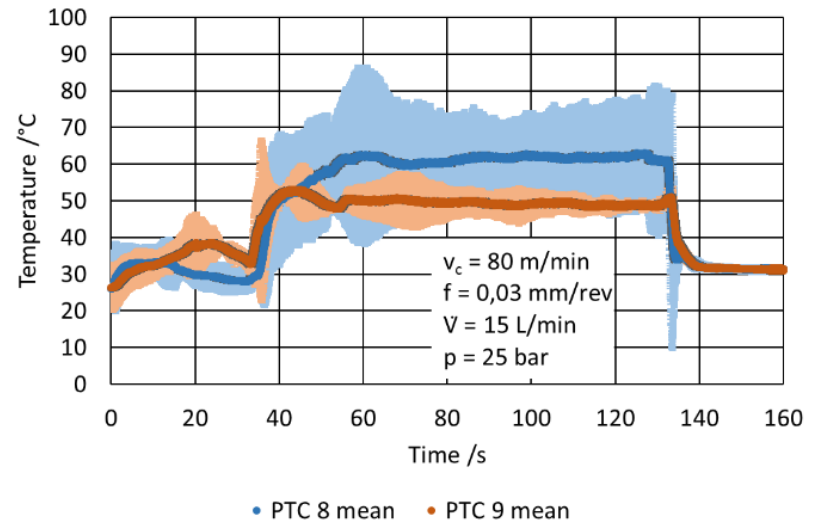

Fig. 7: Temperature curves measured under guide pad 3 on the positions 8 and 9 with use of cooling lubricant.

As shown in Fig. 8, the temperatures are around $32{ }^{\circ} \mathrm{C}$ which is in the same low range as under the other rear guide pad 4.

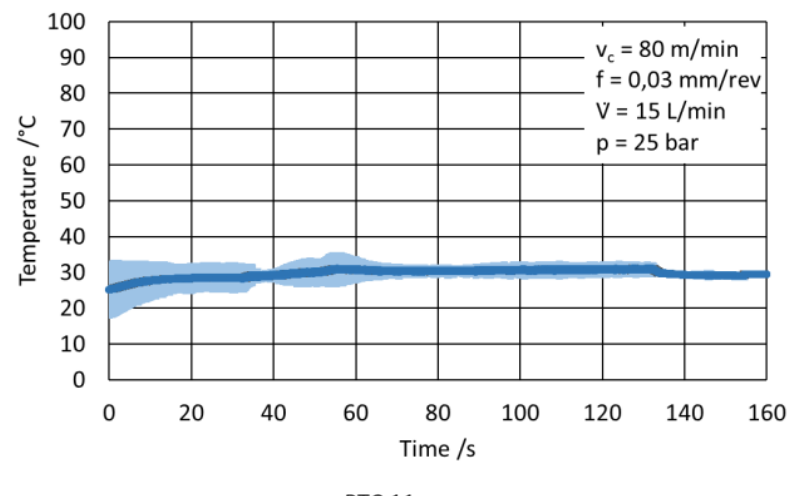

Fig. 8: Temperature curves measured under guide pad 4 on the positions 11 with use of cooling lubricant.

The measured mechanical loads that occurred during this test series shows Fig. 9. The depicted values are mean values of three passes. The feed force increases slightly in the steady state, from approx. $1200 \mathrm{~N}$ up to $1300 \mathrm{~N}$. The drilling torque is around $8 \mathrm{Nm}$.

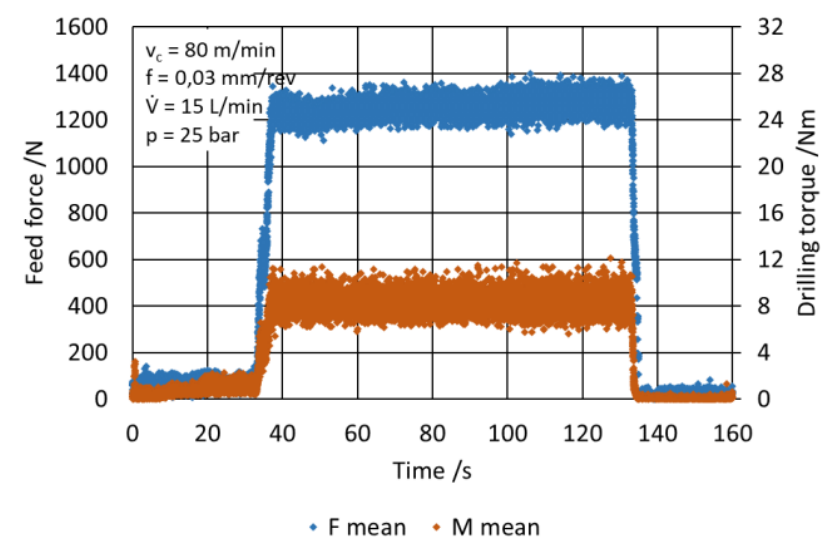

Fig. 9: Feed force and drilling torque curves measured on the workpiece side with use of cooling lubricant (feed force: gain $=333,33 \mathrm{~N} / \mathrm{V}$; bandwidth $=0-10 \mathrm{~V} / 0-3000 \mathrm{~N}$;

$$
f=10 \mathrm{kHz} \text {; drilling torque: gain }=5,405 \mathrm{Nm} / \mathrm{V} \text {; }
$$$$
\text { bandwidth }=0-10 \mathrm{~V} / 0-50 \mathrm{Nm} ; f=10 \mathrm{kHz} \text { ). }
$$

\subsection{Evaluation of the results while dry cutting}

It is interesting to note that the mechanical load in dry drilling tests is even slightly lower than the load in tests with cooling lubricant, see Fig. 10. An explanation for this observation is the material softening due to the high temperatures. The following temperature measurement results provide more information about this observation. In addition, Fig. 10 shows, especially by the drilling torque peak, that mechanical failure of the single-lip deep hole drill occurred after approx. $70 \mathrm{~s}$. Thus, the high temperatures that occur if cooling lubricant is absent are challenging for both the sensor technology and the tool materials. Especially the screws that fix the cutting insert and the guide pads are a weak point.

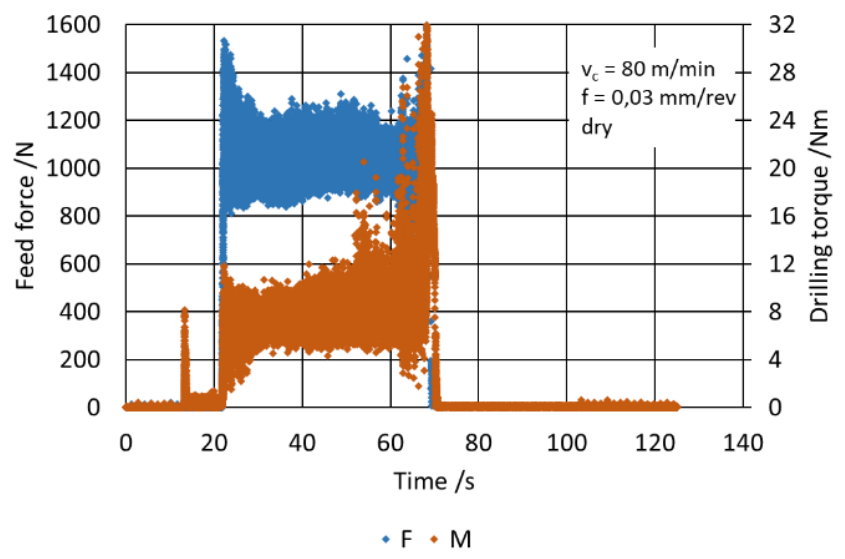

Fig. 10: Feed force and drilling torque curves measured on the workpiece side while dry cutting (feed force: gain $=333,33 \mathrm{~N} / \mathrm{V}$; bandwidth $=0-10 \mathrm{~V} / 0-3000 \mathrm{~N}$;

$f=10 \mathrm{kHz}$; drilling torque: gain $=5,405 \mathrm{Nm} / \mathrm{V}$;

bandwidth $=0-10 \mathrm{~V} / 0-50 \mathrm{Nm} ; f=10 \mathrm{kHz}$ ).

Nevertheless, some temperatures could be recorded, which can be used as a reference for the simulation. The temperature sensors under the two front guide pads 1 and 3 fail between 60 and $70 \mathrm{~s}$ before the steady-state temperature regime was reached, see Fig. 11 and Fig. 12.

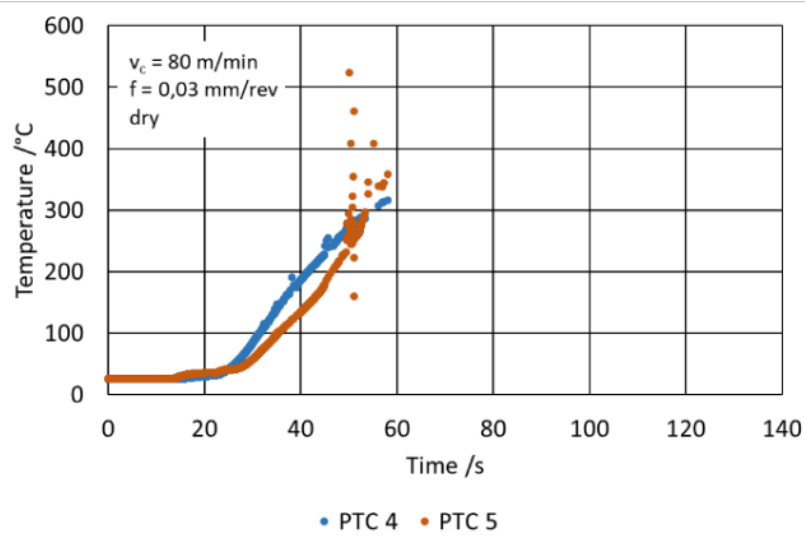

Fig. 11: Temperature curves measured under the guide pad 1 on the positions 4 and 5 while dry cutting.

Fig. 11 and Fig. 12 show clearly, that the temperatures at the front sensors 4 and 8 rush ahead. This means that the position dependent heat flow differences can be detected. Furthermore, it was found that the temperatures at the guide pad 3 behind the cutting insert, with a $163^{\circ}$ offset, are higher at the same time than the temperatures at the guide pad 1 offset by $87^{\circ}$. The same was also observed in the test series with cooling lubricant. 


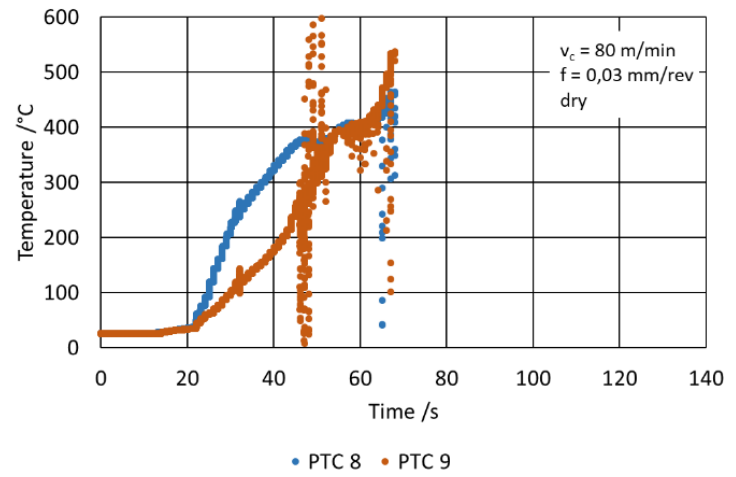

Fig. 12: Temperature curves measured under the guide pad 3 on the positions 8 and 9 while dry cutting.

The temperatures during dry deep drilling at the rear guide pads 2 and 4 are shown in Fig. 13 and Fig. 14. Here as well, significant differences in the gradients and maximum values between the front sensors 6 and 10 and the rear sensors 7 and 11, which are located further away from the heat source, can be determined. This is an important information to describe the heat flow. The temperature during dry drilling at the rear guide pads 2 and 4 is significantly lower than at the front pads 1 and 3 , since the front guide pads in particular smooth the bore wall during forming Consequently, the friction on the rear guide pads is lower.

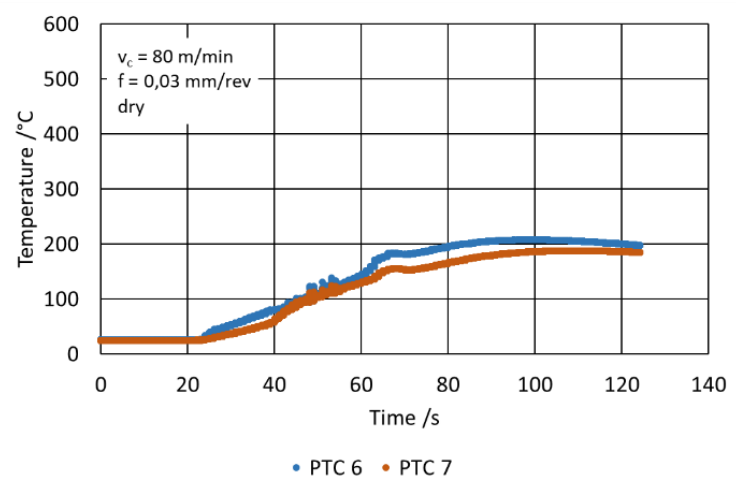

Fig. 13: Temperature curves measured under the guide pad 2 on the positions 6 and 7 while dry cutting.

Comparing the results in Fig. 13 and Fig. 14 with the results from the tests with cooling lubricant in Fig. 6 and Fig. 8, the temperature values without cooling are about $170^{\circ} \mathrm{C}$ higher, even at the rear guide pads where the contact time is the lowest.

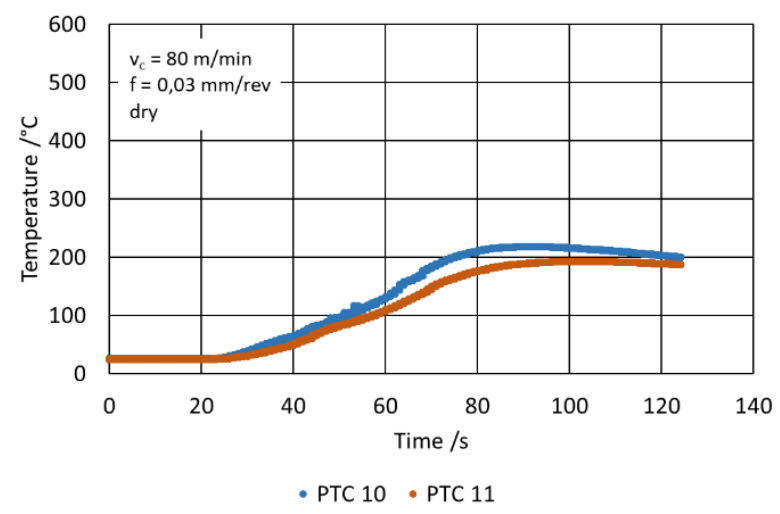

Fig. 14: Temperature curves measured under guide pad 4 on the positions 10 and 11 while dry cutting.

\section{NUMERICAL PROCESS MODELLING}

For modelling the highly dynamic and unsteady process of single lip deep hole drilling in 3D the commercial FE solver ABAQUS was employed with an explicit simulation scheme. The required geometry was provided by the supplying company Guehring KG. In order to decrease the huge simulation effort only the tip of the drill head including two guide pads ( 1 and 3 ) and the cutting insert was considered. Besides, the length of the cylindrical workpiece with a radius of $12.5 \mathrm{~mm}$ was decreased to $5 \mathrm{~mm}$ (Fig. 15). Reducing the complexity of the process the drilling was performed in dry conditions without considering a lubricant. To restrict the movement of the workpiece, the bottom surface as well as the lateral surface was constrained completely. The movement of the driller was applied by linking a reference point above the drill head with all the nodes of the drill head. A general contact was defined between the surface of the drill head and the surface of the workpiece with a hard pressure overclosure correlation, which describes the interaction of the cutting insert and the workpiece in direction orthogonal to the surface. Further selected interaction properties are friction applying a Coulomb friction model with a constant friction coefficient $\mu$ of 0.32 [Pantale 2004] as well as heat generation due to friction converting the deformation-induced energy into heat [Miller 2007]. The full simulation set up is shown in Fig. 15. The leading guide pad in rotational direction is named as guide pad 3 , whereas the succeeding guide pad is defined as guide pad 1.

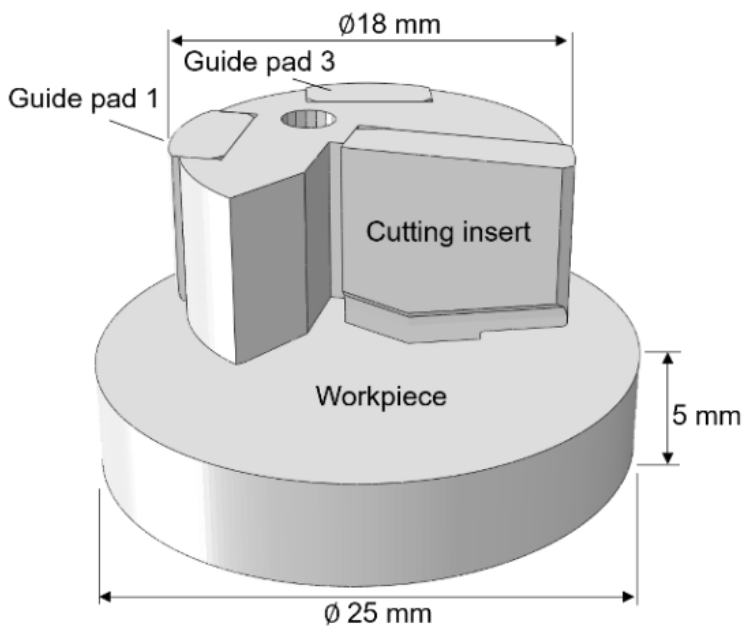

Fig. 15: Set up of the FE simulation model.

The heat generation during the drilling process requires a coupled temperature displacement formulation of the solver, which allows the simulation of heat transfer as well as a stress analysis in parallel. For this purpose, the drill head was created with tetrahedral elements of the type C3D4T and the workpiece with hexahedral elements of the type C3D8RT, respectively. The average element size is $0.1 \mathrm{~mm} \times 0.3 \mathrm{~mm}$. The drill head is considered as a rigid body with infinite stiffness to increase the computational efficiency. However, heat transfer is allowed in the elements to evaluate the temperature distribution within the drill head. The initial temperature of the simulation model was set to $293 \mathrm{~K}$. Two assumptions were made respecting the material behavior of the drill head: all components possess the same material behavior, which is the behavior of cemented carbide, and the material behavior is temperature independent. The assigned thermo-physical properties are summarized in Tab. 1. 
Tab. 1: Thermo-physical properties of the drill head [Fluhrer 2007] and the workpiece [Schulze 2013].

\begin{tabular}{lccc}
\hline & $\begin{array}{c}\text { Density } \\
{\left[\mathrm{g} / \mathrm{cm}^{3}\right]}\end{array}$ & $\begin{array}{c}\text { Conductivity } \\
{[\mathrm{W} / \mathrm{m} \mathrm{K}]}\end{array}$ & $\begin{array}{c}\text { Specific } \\
\text { Heat } \\
{[\mathrm{J} / \mathrm{kg} \mathrm{K}]}\end{array}$ \\
\hline tool & 15.70 & 82.24 & 579.45 \\
\hline workpiece & 7.85 & 34.10 & 610.73 \\
\hline
\end{tabular}

The large deformations and heat generation in the SLD process requires a constitutive law for the workpiece, which is able to cover strain rate as well as temperature dependent plasticity of the workpiece material. Thus, the very common Johnson-Cook (JC) constitutive model is assigned to the workpiece elements [Johnson 1985]:

$$
\sigma=\left(A+B \varepsilon_{p l}^{n}\right)\left(1+C \ln \dot{\varepsilon}_{p l}^{*}\right)\left(1-T^{* m}\right)
$$

where are $A, B, C, n$ and $m$ are the five Johnson-Cook parameters. The variables indexed with a star are the ratio of the actual plastic strain rate $\dot{\varepsilon}_{p l}$ to a standard plastic strain rate $\dot{\varepsilon}_{p l, 0}$ and the actual temperature $T$ to the melting temperature $T_{m}$ and a standard temperature $T_{0}$, respectively. The corresponding JC parameters are summarized in Tab. 2.

Tab. 2: Parameter of the Johnson-Cook constitutive model for this 3D simulation of SLD process [Pantale 2004].

\begin{tabular}{ccccccc}
\hline $\begin{array}{c}\mathrm{A} \\
{[\mathrm{MPa}]}\end{array}$ & $\begin{array}{c}\mathrm{B} \\
{[\mathrm{MPa}]}\end{array}$ & $\mathrm{n}$ & $\mathrm{m}$ & $\mathrm{C}$ & $\begin{array}{c}\mathrm{T}_{0} \\
{[\mathrm{~K}]}\end{array}$ & $\begin{array}{c}\mathrm{T}_{\mathrm{m}} \\
{[\mathrm{K}]}\end{array}$ \\
\hline 595 & 580 & 0,133 & 1,03 & 0,023 & 293 & 1793 \\
\hline
\end{tabular}

The chip formation is modelled by applying a damage model in the simulation. Here, the element elimination technique (EET) was chosen to represent the machining process. Those elements are removed from the FE model, which reach a previously defined critical measure according to the Johnson-Cook damage model [Pantalé 2004].

The applied movement of the drill head was accelerated compared to the experiments to be able to represent at least two complete rotations of the drill head. With the described simulation set up the whole process was modelled successfully within reasonable computational expenses. The resulting evolution of the normalized feed force and the temperature evolution at the outer edge of the cutting insert, the leading guide pad (guide pad 3) and the succeeding guide pad (guide pad 1) is shown in Fig. 16. From the beginning on the feed force increases continuously until full contact of the drill head with the workpiece surface is obtained. Here, the feed force suddenly jumps to a significant higher value. Afterwards, the curve oscillates around a constant value, which can be assumed as a steady state. Comparable behavior is obtained in the experiments under dry conditions (Fig. 10). Due to the higher process parameter compared to the experiment, a high torque of $1000 \mathrm{Nm}$ was calculated in the steady-state. The temperature evolution at the edge of the insert shows a similar but leading behavior. Guide pad 3 shows a higher temperature level, but at later process time. The succeeding guide pad 1 shows a temperature level between the temperatures of the insert and guide pad 3 .

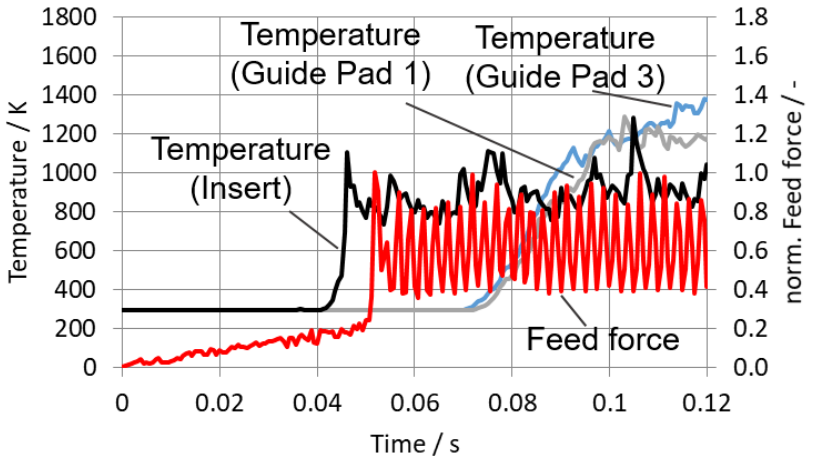

Fig. 16: Evolution of the temperature at the insert and the guide pads 1 and 3 and the feed force in the simulation.

The evaluation of the temperature distribution in the drill head at the end of the simulation delivered different hot spots: The most dominant spot is occurred on the leading guide pad 3, which shows the highest temperature values. However, more positions can be identified: the outer edge of the cutting insert and the succeeding guide pad 1. Besides, the temperature on the edges of the drill head tip starts to increase, too. These hot spots shows the contour plot of node temperature in the drill head in Fig. 17, clearly.

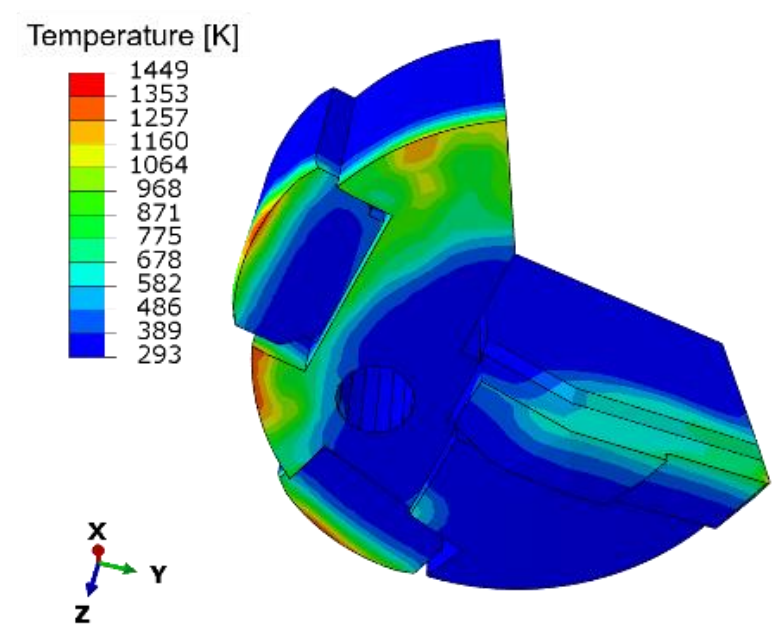

Fig. 17: Contour plot of node temperature in the drill head at the end of the simulation.

Due to the short process time in the cutting simulation, the temperature is not yet distributed over the whole drill head at the end of simulation. However, the observed steadystate conditions in Fig. 16 and expected continuous heat flow lead to the conclusion that the leading guide pad has a higher heat treatment than the cutting insert and the succeeding guide pad. This observation corresponds to the temperature measurements at PTC 3 (insert), 8 (leading guide pad) and 4 (succeeding guide pad) (see Fig. 4, Fig. 5, Fig. 7). Further studies focuses on the reduction of the feed and the cutting velocity and an extension of the simulation time to represent a final temperature distribution.

\section{CONCLUSION}

A sensory tool for monitoring the heat flow in the entire driller head of a single lip deep hole driller was developed and validated. The challenge is to separate the sensor modules from the cooling lubricant considering a constrictive geometry and the use of suitable adhesives. In combination with the mechanical load leading to elastic deformation at the drill head, the cooling lubricant can penetrate to the sensors and causes measurement failure. 
The recorded data can be used to calibrate the heat exchange of the drill head with the environment in an FE simulation. Although the simulated process time was much shorter compared to the experiments, steady-state conditions were reached. This fact allows a correct prediction of the different levels of heat treatment of the drill head components, such as the insert and the guide pads, qualitatively. The predicted feed force evolution is comparable to the experiments under dry conditions, too. The sensory SLD tool and the simulation method are currently under development. Following simulations will focus on the heat transfer between the cutting zone (heat source) and the measurement positions underneath the cutting insert and the guide pads. Furthermore, the reliability and the durability of sensor modules will be improved by decreasing the size and increasing the robustness of the solder joints or the cables. Subsequently, a statistically validated experimental study will be carried out with the improved tool. Reliable in-process measurements of the thermo-mechanical state are fundamental to adjust the drilling conditions via the machining parameters, which lead to defined surface and subsurface properties.

\section{ACKNOWLEDGMENTS}

The authors thank the DFG for this funding and intensive technical support. Also, the authors acknowledge the company Guehring KG for providing technical support.

Funding: The scientific work has been supported by the DFG within the research priority program SPP 2086 under Grant Nos. MO 2091/6-1 and SCHM 746/211-1.

\section{REFERENCES}

[Biermann 2018] D. Biermann, F. Bleicher, U. Heisel, F. Klocke, H.-C. Moehring and A. Shih, "Deep hole drilling," in CIRP Annals Manufacturing Technology, ELSEVIER, 2018, pp. 673-694.

[Davies 2007] M. A. Davies, T. Ueda, R. M'Saoubi, B. Mullany, and A. L. Cooke, "On The Measurement of Temperature in Material Removal Processes," CIRP Annals, vol. 56, no. 2, pp. 581-604, 2007.

[Wegert 2020a] R. Wegert, V. Guski, S. Schmauder, and H.-C. Moehring, "Effects on surface and peripheral zone during single lip deep hole drilling," Procedia CIRP, no. 87, pp. 113-118, 2020.

[Wegert 2020b] R. Wegert, V. Guski, H.-C. Möhring, and S. Schmauder, "Temperature monitoring in the subsurface during single lip deep hole drilling," tm - Technisches Messen, pp. 757-767, 2020.

[Bagci 2006] E. Bagci and B. Ozcelik, "Finite element and experimental investigation of temperature changes on a twist drill in sequential dry drilling," Int J Adv Manuf Technol, vol. 28, 7-8, pp. 680-687, 2006.

[Lazoglu 2017] I. Lazoglu et al., "Thermal analysis in Ti6Al-4V drilling," CIRP Annals, vol. 66, no. 1, pp. 105-108, 2017.

[Wegert 2020c] R. Wegert, V. Guski, S. Schmauder and H.C. Moehring, "Determination of thermo-mechanical quantities with a sensor-integrated tool for single lip deep hole drilling," Procedia CIRP, 5th International Conference on System-Integrated Intelligence, 2020.

[Pantale 2004] O. Pantale, J. L. Bacaria, O. Dalverny, R. Rakotomalala and S. Caperaa, "2D and 3D numerical models of metal cutting with damage effects," Computer methods in applied mechanics and engineering, vol. 193, no. 39-41, pp. 4383-4399, 2004.

[Miller 2007] S. F. Miller and A. J. Shih, "Thermomechanical finite element modeling of the friction drilling process," Journal of Manufacturing Science and Engineering, vol. 129, pp. 531-538, 2007.

[Fluhrer 2007] J. Fluhrer, "DEFORM 3D Version 6.1 User's Manual," Scientific Forming Technologies CorporationSFTC, Ohio, 2007.

[Schulze 2013] V. Schulze, J. Michna, F. Zanger, C. Faltin, U. Maas and J. Schneider, "Influence of cutting parameters, tool coatings and friction on the process heat in cutting processes and phase transformations in workpiece surface layers," HTM Journal of Heat Treatment and Materials, vol. 68, no. 1, pp. 22-31, 2013.

[Johnson 1985] G. R. Johnson and W. H. Cook, "Fracture characteristics of three metals subjected to various strains, strain rates, temperatures and pressures," Engineering fracture mechanics, vol. 21, no. 1, pp. 31-48, 1985. 